\title{
Sobre a dialética entre capital, direito e educação e a necessidade de superação da ideologia jurídica
}

\author{
On the dialectics between capital, law and education and the need to overcome \\ legal ideology
}

\author{
Diogo Mariano Carvalho de Oliveira* \\ Jorge Sobral da Silva Maia**
}

\section{Resumo}

Diante de transformações sociais fugazes e de graduais fissuras nos arranjos sociais contemporâneos, a presente pesquisa entende urgente o agenciamento de perspectivas e proposições críticas que principiem a apreensão efetiva desses novos fenômenos e que ensejem o prelúdio de uma abertura ontológica a novas formas de vida e de sociabilidade, esteandose, para tanto, na breve tentativa de uma análise dialético-materialista do conceito de trabalho, direito e educação, a fim de que seja possível repensar efetivamente a produção concreta desses conceitos. Nesse sentido, propõem-se algumas considerações sobre os conceitos em questão, a fim de apresentar, a partir de uma dada perspectiva teórica e metodológica, uma leitura que suscite tanto o conteúdo efetivo desses conceitos quanto, consequentemente, em formas de repensá-los. Dessa maneira, o objetivo do trabalho é elucidar os conceitos elencados, mas também demonstrar criticamente a necessidade e a possibilidade da superação de seus atuais conteúdos. Para tanto, propõe-se que essa superação depende, essencialmente, da capacidade de se repensar os efeitos da ideologia jurídica, assim como de superar o atual bloco histórico, através da articulação de disputas hegemônicas que rompam ontologicamente com o atual estado de coisas e inaugurem uma nova forma de vida.

Palavras-chave: Crítica do direito. Marxismo. Ideologia. Educação.

\section{Abstract}

In times of fleeting social transformations and gradual fissures in the contemporary social arrangements, the present research understand urgent the agency of critical perspectives and propositions that begins the actual apprehension of these new phenomena and that lead the prelude of an ontological opening to new forms of life and sociability, thus supporting the brief attempt of a brief dialectical-materialist analysis of capital, law and education, so that it is possible to effectively rethink the concrete production of these concepts. In this sense, the present research proposes some considerations about the concepts in question in order to present, from a given theoretical and methodological perspective, a reading that raises both the effective content of these concepts and, consequently, ways of rethinking them. In this way the objective of the work is to elucidate the concepts listed, but also to critically demonstrate the need and the possibility of overcoming its current contents. In order to do so, it is proposed that this overcoming depends essentially on the capacity to rethink the effects of legal ideology, as well as to overcome the current historical block through the articulation of hegemonic disputes that break ontologically with the current state of affairs and inaugurate a new way of life.

Keywords: Critique of the law. Marxism. Ideology. Education.

Mestre no Programa de Mestrado em Ciência Jurídica da Universidade Estadual do Norte do Paraná - UENP. Graduado em Direito na Universidade Estadual do Norte do Paraná - UENP. Militante do coletivo Círculo de Estudos da Ideia e da Ideologia - CEII. Jacarezinho - PR - Brasil. E-mail: diogo.carvalho92@hotmail.com.

Doutor em Educação para a Ciência pela Faculdade de Ciências da UNESP, consultor do Instituto Nacional de Estudos e Pesquisas Educacionais Anísio Teixeira (INEP), Professor Adjunto do Programa de Pós-graduação em Ciências Jurídicas da UENP, Professor Adjunto do Centro de Ciências Humanas da UENP e Coordenador do Laboratório de Ensino e Pesquisa em Educação para a Ciência. Jacarezinho - PR - Brasil. E-mail: sobralmaia@uenp.edu.br. 


\section{Introdução}

Vivemos tempos minimamente obscuros, para não dizermos catastróficos, de um ponto de vista antropológico. O primeiro quarto do século XXI veio para mostrar que ele não será para quem tem nervos fracos, nem para quem não está apto a mudanças radicais: o desenvolvimento das forças produtivas; a ameaça da reorganização dos atuais sistemas de produção, baseados na exploração da mão de obra humana em processos produtivos automatizados e altamente tecnológicos; o crescimento desenfreado dos espaços virtuais e das mídias sociais; o aumento das polarizações políticas e dos discursos de ódio; a intensificação da agenda globalizante e a consecutiva intensificação militar das fronteiras diante do intumescimento da massa de refugiados; a crescente consolidação da circulação do capital fictício e o consequente retorno das relações pessoais de dominação direta; o ascendente esgotamento dos recursos naturais; a multiplicação desenfreada da especulação financeira; a hiperinflação acumulativa de capital improdutivo, etc.

Nesse sentido, é premente reabilitar as armas da crítica e retomar uma análise diligente e metódica de relações, mecanismos, fluxos, articulações e processos, os quais que estruturam e organizam a totalidade concreta, a fim de que seja possível pensar, e não apenas alguns primeiros e pequenos passos que nos permitam imprimir ajustes e correções aos problemas e impasses atuais, mas que também nos habilitem a pensar e propor novas formas de organização social, principiando uma linha de fuga do atual ciclo repetitivo de proposições paliativas e temporárias, que nos conceda propor soluções definitivas. Mais precisamente, que nos permita conceber e apostar em novas formas de vida e de sociabilidade.

Tentaremos, portanto, ao longo do exposto, apresentar alguns elementos que nos autorizem pensar os fundamentos que constituem nosso modo de organização social corrente e, ao mesmo tempo, levantar propostas e noções que abram espaço para a reflexão sobre novos horizontes. Faremos isto a partir de uma análise dialético-materialista de três categorias que entendemos centrais para a compreensão do problema: o conceito de trabalho, o conceito de educação e o conceito de direito.

\section{Um conceito marxista de trabalho}

Com o desenvolvimento da obra de Marx, tornou-se possível compreender o trabalho como uma categoria cujo conceito se configura sob condições bastante precisas. Não se trata mais de compreender o trabalho simples, em termos ontológico-naturalistas, como atividade de metabolização da natureza. De fato, Marx primeiramente apresenta como seria possível tomar o trabalho de modo imediato, isto é, enquanto "aparência" (Schein), mas o trabalho como um mecanismo de metabolismo social do homem diante da vida não é o trabalho tomado como conceito, e sim como certeza imediata. Nesse sentido, o trabalho é o processo através do qual o homem coloca suas forças naturais em disputa com a natureza com a finalidade de garantir sua sobrevivência.

\footnotetext{
O trabalho é, antes de tudo, um processo entre o homem e a natureza, processo este em que o homem, por sua própria ação medeia, regula e controla seu metabolismo com a natureza. Ele se confronta com a matéria natural como com uma potência natural [Naturmacht]. A fim de se apropriar da matéria natural de uma forma útil para sua vida, ele põe em movimento as forças naturais pertencentes a sua corporeidade: seus braços e pernas, cabeças e mãos. Agindo sobre a natureza externa e modificando-a por meio desse movimento, ele modifica, ao mesmo tempo, sua própria natureza. Ele desenvolve as potências que nela jazem latentes e submete o jogo de suas forças a seu próprio domínio (MARX, 2013, p. 255).
}

Mas não é esse o tipo de trabalho a que Marx se refere e que analisa em sua obra "O capital". Nesta obra, Marx quer demonstrar que a noção fundamental de trabalho não reside essencialmente na ideia de atividade produtiva, mas no fato de que ele surge na sociedade capitalista como dispêndio de trabalho humano.

Abstraindo-se da determinidade da atividade produtiva e, portanto, do caráter útil do trabalho, resta o fato de que ela é um dispêndio de força humana de trabalho. Alfaiataria e tecelagem, embora atividades 
produtivas qualitativamente distintas, são ambas dispêndio produtivo de cérebro, músculos, nervos, mãos e etc. humanos e, nesse sentido, ambas são trabalho humano. Elas não são mais que duas formas diferentes de se despender força humana de trabalho. No entanto, a própria força humana de trabalho tem de estar mais ou menos desenvolvida para poder ser despendida desse ou daquele modo. Mas o valor da mercadoria representa unicamente o trabalho humano, dispêndio de trabalho humano (MARX, 2013, p. 121-122).

A abstração da determinidade do trabalho como atividade produtiva útil nos revela sua natureza essencial: ele é dispêndio de trabalho humano. Contudo, não é apenas isso: o trabalho aparece no sistema de produção e circulação de mercadorias do modo de produção capitalista como o processo através do qual o valor de uso é formado. A mercadoria expressa, assim, tanto a quantidade de trabalho abstrato quanto o resultado efetivo de um trabalho concreto.

Dessa forma, o trabalho aparece em seu duplo caráter: ele se manifesta como trabalho concreto, isto é, como o modo através do qual o homem efetivamente molda e produz um novo objeto através do dispêndio de sua força de trabalho de maneira específica e individualizada e, por outro, apresenta-se como trabalho abstrato, ou seja, como processo a partir do qual se torna possível gerar o valor das mercadorias através da quantificação do dispêndio de força humana de trabalho. Essa quantificação revela-se como o tempo socialmente necessário para a produção das mercadorias.

Todo trabalho é, por um lado, dispêndio de força humana de trabalho em sentido fisiológico, e graças a essa sua propriedade de trabalho humano igual ou abstrato ele gera o valor das mercadorias. Por outro lado, todo trabalho é dispêndio de força humana de trabalho numa forma específica, determinada à realização de um fim, e, nessa qualidade de trabalho concreto e útil, ele produz valores de uso (MARX, 2013, p. 124).

Entretanto, no modo de produção capitalista, por ser o trabalho a atividade que gera o valor das mercadorias, o trabalhador surge como a mais valiosa das mercadorias, já que ele é a única mercadoria, dentre todas as outras, capaz de cristalizar certa quantidade de valor num outro objeto que não ele mesmo. O trabalhador se revela uma mercadoria singular, a única que é capaz de produzir valor de uso e transferila para outra mercadoria.

O trabalhador se torna tanto mais pobre quanto mais riqueza produz, quanto mais a sua produção aumenta em poder e extensão. O trabalhador se torna uma mercadoria tão mais barata quanto mais mercadorias cria. Com a valorização do mundo das coisas (Sachenwelt) aumenta em proporção direta a desvalorização do mundo dos homens (Menschenwelt). O trabalho não produz somente mercadorias; ele produz a si mesmo e ao trabalhador como uma mercadoria, e isto na medida em que produz, de fato, mercadorias em geral (MARX, 2010, p. 80).

Isto ocorre essencialmente em razão de um processo contínuo de estranhamento, ou alienação (Entfremdung ${ }^{1}$ ), ao qual o trabalhador é inevitavelmente submetido e cuja natureza é essencialmente estrutural. As mercadorias que o trabalhador produz não pertencem efetivamente a ele, mas aos proprietários dos modos de produção, levando o trabalhador a não se reconhecer em sua atividade e na mercadoria que produz.

[...] na elaboração do mundo objetivo o homem se confirma, em primeiro lugar e efetivamente, como ser genérico. Esta produção é a sua vida genérica operativa. Através dela a natureza aparece como a sua obra e a sua efetividade (Wirkilichkeit). O objeto do trabalho é, portanto a objetivação da vida genérica do homem: quando o homem se duplica não apenas na consciência, intelectual[mente], mas operativa,

\footnotetext{
De acordo com Paulo Meneses (2001), os termos "Entfremdung" e "Entäusserung" possuem diferentes traduções na obra hegeliana - léxico do qual Marx empresta os termos. Segundo o tradutor da edição brasileira de "Fenomenologia do Espírito", de G. W. F. Hegel, os dois termos foram importados imprecisamente por Marx, que, muitas vezes, os confunde ou os emprega num sentido diverso daquele presente na Fenomenologia. Segundo Meneses (2001), "Entfremdung" conduz à ideia de alienação ou alheação de si mesmo, de tornar-se estranho a si. Esse termo traz consigo a noção de perda, de subtração, de "dessenciamento". Já em "Entäusserung" o que se denota é a força da extrusão, de um pôr-se para fora de si mesmo sem qualquer tipo de perda ou dessenciamento. Em "Entäusserung" verificamos a "externalização" ou "exteriorização" de si através de uma objetivação, um fazer-se ser fora-de-si sem aquele "dessenciamento" característico do "Entfremdung".
} 
efetiva[mente], contemplando-se, por isso, a si mesmo num mundo criado por ele. Consequentemente, quando arranca (entreisst) do homem o objeto de sua produção, o trabalho estranhado arranca-lhe sua vida genérica, sua efetiva objetividade genérica (wirklicheGatungsgegenständlichkeit) e transforma a sua vantagem com relação ao animal na desvantagem de lhe ser tirado o seu corpo inorgânico, a natureza (MARX, 2010, p. 85).

No sistema capitalista, é preciso que isto ocorra para que o capitalista se aproprie dos excedentes econômicos da atividade comerciária, já que ele depende desse processo de alienação para manter a taxa de mais-valor, isto é, garantir que o trabalhador continue vendendo sua força e seu tempo de trabalho - e, portanto, continue se desfazendo de sua própria vida -, expropriando uma quantidade de trabalho que, na verdade, não é paga. O mais-valor não é um tempo de trabalho sub-remunerado, mas um tempo de trabalho que não é pago de forma alguma, mantendo-se acumulado no circuito da produção das mercadorias.

Ainda assim, é preciso aclarar a sentido das categorias marxianas. Marx não está apenas dizendo que o trabalho é o modo de objetivação da vida genérica dos indivíduos, mas que, no capitalismo, essa atividade genérica produtiva desenvolvida pelo homem aparece sob o signo do trabalho. $O$ trabalho é, pois, a forma como essa atividade produtiva genérica se manifesta em nosso tempo. Um ser genérico que ganha especificidade histórica e recebe um signo próprio que dá forma ao seu conceito.

Ao produzir valores de uso, o trabalho no capitalismo pode ser visto como uma atividade intencional que transforma o material de maneira determinada - o que Marx denomina de 'trabalho concreto'. A função do trabalho como atividade socialmente mediante é o que ele chama de 'trabalho abstrato'. Vários tipos do que ele poderia considerar trabalho existem em todas as sociedades (mesmo que não na formal geral 'secularizada' originada pela categoria do trabalho concreto), mas o trabalho abstrato é específico do capitalismo e, portanto, justifica um exame mais detalhado. [...] A categoria do trabalho abstrato não se refere a um tipo particular de trabalho nem ao trabalho concreto em geral; pelo contrário, ela expressa uma função social única do trabalho no capitalismo além da sua função 'normal' como atividade produtiva (POSTONE, 2014, p. 176).

Pretendemos ir mais fundo nessa crítica. Nossa hipótese é de que não há uma real cisão entre as categorias de trabalho concreto e trabalho abstrato - subsumidas sob a categoria "trabalho". Na verdade, essas categorias compõem o anverso de uma mesma moeda, de tal forma que não podem ser separadas. Não é possível tratar, em termos conceituais, de trabalho concreto e trabalho abstrato como categorias autônomas, que seriam consistentes em si mesmas e exerceriam funções absolutamente autônomas, formando uma categoria de trabalho bipartida. Sendo o verso e anverso de uma mesma moeda - que nos aparece sob a categoria "trabalho" -, ambas as categorias só podem ser vistas como fenômenos de um único movimento, similar ao que percebemos numa "fita de Möbius" ou numa "garrafa de Klein". ${ }^{2}$ Isto quer dizer que não há trabalho concreto e trabalho abstrato separadamente, pois ambas as categorias só existem a partir do nexo conceitual que as liga e as transforma na imagem singular e biunívoca do conceito de trabalho. O trabalho não é, pois, como Marx parece apontar nos Manuscritos Econômico-Filosóficos, uma categoria trans-histórica (ou anistórica), ontológica, de valor atemporal e universal, mas uma categoria historicamente específica. Não é a atividade produtiva que aponta um conceito genérico de trabalho, mas o trabalho que aponta para um conceito historicamente específico de atividade produtiva genérica.

O 'trabalho' é ele mesmo um fenômeno histórico. Em sentido estrito, o trabalho só existe nas circunstâncias em que existam o trabalho abstracto e o valor. Não só no plano lógico, mas também em relação ao trabalho, 'concreto' e 'abstrato' são expressões que remetem uma para a outra e que não podem existir uma independentemente da outra. [...] Não se pode simplesmente opor entre si o trabalho abstracto e o trabalho concreto, e ainda menos se pode opô-los como se fosse o 'mal' e o outro o 'bem'. O conceito de trabalho concreto é ele mesmo uma abstracção, porque nele se separa, no espaço e no tempo, uma certa forma de atividade do campo conjunto das atividades humanas:

A fita de Möbius e a garrafa de Klein são figuras topológicas, conceitos espaciais da matemática que abordam graficamente a noção de orientabilidade. Ambas as figuras são caracterizadas pela disposição de uma superfície em que não é possível determinar precisamente um interior e um exterior, um dentro e um fora. O que elas propõem, portanto, é pensar um espaço sem limite, sem cisão, ou seja, pura unidade contínua. Propomos, assim, que o conceito seja pensado como uma dessas figuras da topologia, em que se torna impossível determinar onde e quando há apenas trabalho concreto e onde e quando há apenas trabalho abstrato, separadamente. Essas categorias aparecem como irradiações, colorações, reflexos da paralaxe do observador que olha a fita, inexistindo efetivamente um lugar bem definido para cada uma delas. 
o consumo, o jogo e a diversão, o ritual, a participação nos assuntos coletivos, etc. Um homem da época pré-capitalista nunca teria tido a ideia de colocar no mesmo nível ontológico, enquanto 'trabalho' humano, coisas tão diversas com a fabricação de um pão, a execução de uma peça musical, a condução de uma campanha militar, a descoberta de uma figura geométrica e a preparação de uma refeição. A categoria do trabalho não é ontológica, antes existe apenas nas circunstâncias em que existe o dinheiro como forma habitual da mediação social. Mas, se a definição capitalista do trabalho abstrai de todo e qualquer conteúdo, isso não significa que todas as atividades no modo de produção capitalista sejam consideradas como 'trabalho': só é considerada como tal a atividade que produz valor e se traduz em dinheiro ${ }^{3}$ (JAPPE, 2006, p. 110-111).

O trabalho se apresenta a partir dessas duas facetas ou funções: abstrato e concreto. Se, por um lado, é o trabalho que, sob sua acepção abstrata, consegue condensar numa categoria uma série de atividades produtivas específicas e qualitativamente diferentes, mas que se submetem a um mesmo padrão de medida - o valor-de-troca ou a forma-valor -; por outro, o próprio trabalho, em sua acepção concreta, está sobredeterminado por sua função abstrata. O trabalho concreto só existe, assim, em função de sua figura abstrata, e vice-versa. $O$ trabalho enquanto conceito e categoria histórica do modo de produção capitalista deve ser entendido como modalidade específica da noção genérica de atividade produtiva que Marx nos apresenta nos Manuscritos. Sob esses termos, o trabalho se apresenta para nós como categoria fundamental do modo de sociabilidade moderno. Todavia, nesse mesmo movimento, o presente conceito de trabalho também nos permite entrever que é possível pensar em formas de vida para além do trabalho - entendido conceitualmente - e do valor. Formas de vida que poderão despontar num horizonte próximo apenas a partir de uma revolução das matrizes epistemológicas que constituem o sujeito moderno.

Nesse sentido, parece-nos relevantes refletir sobre a atividade educativa onmilateral, ${ }^{4}$ cujos elementos objetivos se revelam emancipatórios, uma vez que através dela tenciona-se buscar uma ampla formação humana em suas múltiplas possibilidades, construindo relações sociais articuladas à práxis e à sociabilidade livres e, portanto, sem alienação (Entfremdung). É o que faremos a seguir, considerando as circunstâncias em que se produz a vida na sociedade capitalista e nos inquirindo que tipo de formação é possível em tais circunstâncias com vistas à sua superação. Para isso, é necessário compreender que:

[...] no capitalismo a atividade produtiva é acentuadamente marcada pelo caráter alienado/estranhado que nega o homem e o trabalho enquanto atividade de manifestação humana. Portanto, o homem que se apresenta como expressão das relações sociais burguesas é um homem alienado/estranhado, tanto o que se apropria dos produtos do trabalho alheio quanto o produtor direto, que é desapropriado. Os indivíduos, em geral, independentemente do lugar que ocupam na dinâmica econômico-social, encontram-se sob a égide do capital, numa sociabilidade em que se impõe de maneira universalizante a forma mercadoria como forma de realização fetichizada do trabalho e do intercâmbio entre os indivíduos (JUSTINO, 2010, p. 75).

\footnotetext{
Ainda: “O conceito de 'trabalho concreto' é igualmente uma ficção; na realidade o que existe é uma multiplicidade de actividades concretas. E as mesmas afirmações são válidas no que respeita ao valor de uso: o valor de uso está ligado ao valor como um dos pólos magnéticos que está ligado ao outro. O valor de uso não poderia subsistir por si só; não representa, pois, o lado 'bom' ou 'natural' da mercadoria que pudesse opor-se ao lado 'mau', abstracto, artificial, exterior. Esses dois lados estão ligados um ao outro da mesma maneira que, por exemplo, o capital e o trabalho assalariado, e só poderão desaparecer conjuntamente. O facto de algo ter um 'valor de uso' mais não exprime do que a capacidade - abstracta de esse algo satisfazer uma necessidade qualquer. Segundo Marx, o valor de uso torna-se um 'caos abstracto', logo que sai da esfera separada da economia. O verdadeiro contrário não é o valor de uso, mas sim a totalidade concreta de todos os objectos." (JAPPE, 2006, p. 112).

4 A noção de omnilateralidade presente na tradição marxista busca conceber a ideia de autorrealização do homem enquanto ser genérico a partir da convergência de sua atividade produtiva com sua própria instrução em geral. Trata-se de compor novas formas de intercâmbio metabólico com a natureza, de modo que o homem se realize através de múltiplas e livres relações com os meios que lhe cercam; de retirar os homens de seus desenvolvimentos unilaterais, de dissolver os princípios de egoísmo atomizado, a partir da constituição de uma nova forma de sociabilidade que realize efetivamente a liberdade do homem. Isto requer a concepção de uma forma de vida que irrompa das ruínas do horizonte capitalista; a fundação de uma ontologia geradora de um novo homem que dissolva as limitações do estreito homem capitalista. Marx e Engels nos apontam algumas linhas prematuras sobre esse novo tipo de homem que poderá surgir como resultado insólito de um arranjo social ainda por vir: "Se o homem forma todos os seus conhecimentos, suas sensações etc. do mundo sensível e da experiência dentro desse mundo, o que importa, portanto, é organizar o mundo do espírito de tal modo que o homem faça aí a experiência, e assimile aí o hábito daquilo que é humano de verdade, que se experimente a si mesmo enquanto homem. Se o interesse bem-entendido é o princípio de toda moral, o que importa é que o interesse privado do homem coincida com o interesse humano. Se o homem não goza de liberdade em sentido materialista, quer dizer, se é livre não pela força negativa de poder evitar isso e aquilo, mas pelo poder positivo de fazer valer sua verdadeira individualidade, os crimes não deverão ser castigados no indivíduo, mas [devem-se] sim destruir as raízes antissociais do crime e dar a todos a margem social necessária para exteriorizar de um modo essencial sua vida. Se o homem é formado pelas circunstâncias, será necessário formar as circunstâncias humanamente. Se o homem é social por natureza, desenvolverá sua verdadeira natureza no seio da sociedade e somente ali, razão pela qual devemos medir o poder de sua natureza não através do poder do indivíduo concreto, mas sim através do poder da sociedade" (MARX; ENGELS, 2011, p. 149-150).
} 
Essa afirmação, evidentemente, implica em compreendermos que as relações alienadas inviabilizam a omnilateralidade, uma vez que a atividade vital livre pressupõe o ser humano não alienado e somente efetiva-se em uma sociabilidade livre, pois implica em determinações humanas só possíveis na totalidade livre das opressões impostas pelo modo atual de se produzir a vida em sociedade. É necessário, portanto, uma educação que vá além do capital; uma educação que seja crítica, emancipatória e transformadora. Mais do que isso, que tenha em seu horizonte de realização a própria dissolução e reinvenção de si mesma.

\title{
3 Uma abordagem sobre a educação
}

O trabalho educativo é um processo social que possibilita a formação da humanidade nos seres humanos. Essa afirmação permite compreender a educação como forma de inserção das pessoas no universo da cultura produzida socialmente e acumulada historicamente pelo conjunto dos homens e mulheres ao longo da história da humanidade (SAVIANI, 2005). A cultura aqui pode ser entendida como o "produto das leis históricas determinadas pelas condições concretas da existência humana e, assim sendo, o homem nessa perspectiva produz cultura, mas também é fruto das relações sociais, que são internalizadas por ele e que se expressam na forma de funções psíquicas" (MARTINS, 2011, p. 345).

O que se verifica na afirmação anterior é que a cultura é fruto do trabalho humano e, portanto, se expressa na história. À medida que os homens e mulheres, por meio do trabalho, foram transformando a natureza, transformaram a si mesmos e também produziram cultura. Pode-se entender ainda que a natureza é a base e o fundamento para o surgimento da cultura. Todavia, ela não é dada aos seres humanos. Estes precisam produzi-la sob condições materiais específicas que se expressam nas próprias produções culturais.

Partindo do exposto anteriormente, é possível afirmar que os seres humanos estão condicionados pelos meios natural e cultural. Sobre essa questão, Saviani (2007, p. 44) explica que:

\begin{abstract}
O homem depende do espaço físico, clima, vegetação, fauna, solo, subsolo. Mas não é só o meio puramente natural que condiciona o homem. Também o meio cultural que se impõe a ele inevitavelmente. Já ao nascer, além de uma localização geográfica mais ou menos favorável, o homem defronta-se com uma época de contornos históricos precisos, marcada pelo peso de uma tradição mais ou menos longa, com uma língua já estruturada, costumes e crenças definidos, uma sociedade com instituições próprias, uma vida econômica peculiar e uma forma de governo ciosa de seus poderes. Esse é o quadro da existência humana.
\end{abstract}

Verifica-se, pelo exposto, que há uma dupla natureza na constituição dos seres humanos: uma própria da constituição da espécie de caráter biológico e outra social, dada pela interação dos indivíduos em comunidade. Nessa interação, assimilam-se elementos da cultura e da tradição que se firmaram ao longo da história de um povo em determinada época e lugar. Esse conhecimento adquirido permite ao ser humano viver satisfatoriamente bem.

Os gregos denominam esse conhecimento de doxa, isto é, "certo juízo subjetivo que tem valor apenas momentâneo, um juízo que não poderá ser referência ética, pois tem presente a possibilidade da falsidade das crenças que suportam a ação" (FRANKLIN, 2004, p. 374). Essa concepção é buscada pela autora citada em Platão, que, em suma, entende doxa como o oposto ao cientificamente instituído.

Nessa linha, a episteme, a partir de Platão, refere-se ao conhecimento metódico e sistemático, o conhecimento científico, ou ainda o campo da filosofia que indica de modo geral, isto é, as possibilidades, valores, do conhecimento científico, seus limites e o que uma determinada atividade humana precisa para se integrar à ciência. Pode-se afirmar, portanto, que a epistemologia refere-se ao conhecimento produzido pela humanidade em sua amplitude, natureza e razão (MOREIRA; MASSONI, 2011).

Nesse sentido, é necessário compreender a natureza do ser humano, sua existência e realidade, de modo a pensar o que constitui os seus meios de interação com a natureza e o que engendra suas matrizes epistemológicas. Essa afirmação nos remete à questão ontológica e, mais do que isso, à crítica ontológica.

Entendemos por crítica ontológica, considerando a natureza, a existência e a realidade humana, a crítica ao modo de produzir a vida na sociedade do capital. Além disso, afirmamos que é preciso avançar, 
por meio da crítica, para uma articulação que nos leve à compreensão de que é urgente superar as atuais fragmentações presentes contra a violência, as injustiças, os preconceitos e a opressão. É evidente que as lutas que realizamos, mesmo que fragmentadas, são fundamentais, mas elas acabam por dividir as forças que buscam a transformação social do modo de produzir em sociedade. Todavia:

\begin{abstract}
Não há dúvidas que elas continuarão sendo lutadas, pois emergem espontaneamente das infâmias e perversidades de nossa sociedade. Seu destino, porém, tem sido a dissolução no varejo, seja na derrota, seja nas conquistas consentidas, aceitáveis, assimiláveis. Estas lutas não tem sido capazes de convergir para algo que possa abalar as estruturas da moderna sociedade capitalista. Parece urgente, a meu ver, perguntar pelas razões dessa incapacidade antes de tudo porque é evidente que as revoltas e as lutas contra a violência, a miséria, a infâmia etc. não podem por si mesmas acabar com a violência, a miséria, a infâmia etc., pois se fossem capazes, nunca teriam existido. A primeira violência, a primeira miséria ou a primeira opressão teria gerado a luta que a teria imediatamente abolido (DUAYER, 2015, p. 116).
\end{abstract}

Parece que, para superar esse impasse, é necessário formar quadros que sejam capazes de elaborar uma crítica ontológica radical do capital e de suas estruturas, que potencialize as lutas políticas, dando sentido a elas, com vista a outra hegemonia, que implique no resgate da filosofia da práxis como fundamento para a crítica ontológica.

Do ponto de vista educativo, para que se atinja outra hegemonia, é premente a necessidade de uma pedagogia que supere as concepções não críticas e crítico reprodutivistas do processo educativo, pois tendem a marginalizar aqueles que sofrem as mazelas impostas pelo modo capitalista de produzir (tabela 1). Verifica-se, pois, a inevitabilidade de uma concepção pedagógica afinada com a transformação social, econômica e política; uma pedagogia crítica de fundo materialista histórico-dialético que forneça aos oprimidos e aos marginalizados pelo sistema, os trabalhadores e seus filhos, os fundamentos e instrumentos para enfrentar as dinâmicas do capital.

Quadro1: Teorias pedagógicas e suas concepções de marginalidade

\begin{tabular}{|c|c|c|}
\hline \multicolumn{3}{|l|}{ Teorias não críticas } \\
\hline Pedagogia tradicional & Pedagogia nova & Pedagogia tecnicista \\
\hline $\begin{array}{l}\text { A causa da marginalidade } \\
\text { é a ignorância, a falta de } \\
\text { esclarecimento. A escola visa } \\
\text { equalizar o problema. }\end{array}$ & $\begin{array}{l}\text { A marginalidade se relaciona não } \\
\text { mais com a ignorância e sim com a } \\
\text { rejeição. Ao adequar-se o indivíduo } \\
\text { à sociedade resolve-se o problema. }\end{array}$ & $\begin{array}{l}\text { A marginalidade relaciona-se a } \\
\text { incompetência técnica. Marginal } \\
\text { é o improdutivo. Resolve-se o } \\
\text { problema à medida que se forma } \\
\text { indivíduos eficientes. }\end{array}$ \\
\hline \multicolumn{3}{|l|}{ Teorias crítico-reprodutivistas } \\
\hline $\begin{array}{l}\text { Teoria do sistema de ensino como } \\
\text { violência simbólica }\end{array}$ & $\begin{array}{l}\text { Teoria da escola como aparelho } \\
\text { ideológico do estado }\end{array}$ & Teoria da escola dualista \\
\hline $\begin{array}{l}\text { A marginalidade é oriunda da falta } \\
\text { de capital econômico e capital } \\
\text { cultural. }\end{array}$ & $\begin{array}{l}\text { A marginalidade funda-se na } \\
\text { expropriação material dos } \\
\text { trabalhadores pelo capital e sua } \\
\text { lógica. }\end{array}$ & $\begin{array}{l}\text { A marginalidade se dá pela escola } \\
\text { que converte a classe operária em } \\
\text { marginal. }\end{array}$ \\
\hline
\end{tabular}

Fonte: Modificado de Maia (2011) a partir de Saviani (2001).

Para entender a questão da marginalidade em relação às teorias pedagógicas da educação, é fundamental discutir os fatores sócio-históricos determinantes.

[...] no que diz respeito a respeito questão da marginalidade, as teorias educacionais podem ser classificadas em dois grupos. No primeiro temos aquelas teorias que entendem ser a educação um instrumento de equalização social e, portanto, de superação da marginalidade. No segundo, estão as teorias que entendem ser a educação um instrumento de discriminação social, logo um fator de marginalização (SAVIANI, 2001, p. 95). 
Entende-se, portanto, que as teorias educacionais não críticas e as crítico-reprodutivistas articulamse à escola capitalista e, como tal, precisam ser problematizadas e superadas. Para isto, é importante considerar a forma como vivem e atuam as pessoas em sociedade, reconhecer suas práticas sociais em seus contextos, e qualificá-las para atuarem nas diversas circunstâncias da vida.

A concepção de prática social que trazemos aqui é o ponto de partida do processo educativo, da ação do professor (por exemplo, em uma pedagogia de caráter materialista dialético), mas também é o ponto de chegada nesse mesmo processo:

\begin{abstract}
Neste primeiro momento, o professor tem uma 'síntese precária', pois há conhecimento e experiências em relação à prática social, mas seu conhecimento é limitado, pois ele ainda não tem claro o nível de compreensão dos seus alunos. Por sua vez, a compreensão dos alunos é sincrética, fragmentada, sem a visão das relações que formam a totalidade. O primeiro momento do método articula-se como o nível de desenvolvimento efetivo do aluno, tendo em vista adequação do ensino aos conhecimentos já apropriados e ao desenvolvimento iminente, no qual o ensino deve atuar. Com isso se quer dizer que esse momento deve, com base nas demandas da prática social (o que não é sinônimo de demandas do cotidiano), selecionar conhecimentos historicamente construídos que devam ser transmitidos, traduzidos em saber escolar. O ponto de partida da prática educativa é a busca pela apropriação, por parte dos alunos, das objetivações humanas (MARSIGLIA, 2011, p. 23-24).
\end{abstract}

Essa pedagogia possibilita entender as questões da prática social, gerando condições para sua problematização. Todavia o fundamento para problematizar a prática social não dispensa os conhecimentos sistematizados, que demonstram os processos em sua totalidade e complexidade, indo além da simples compreensão cotidiana dos fenômenos.

Problematizar a prática social por meio de abstrações teóricas que possibilitam o saber elaborado, isto é, a ciência, a filosofia e a arte, propicia a aquisição de instrumentos que levam ao acesso do saber elaborado, tanto do ponto de vista teórico como prático, qualificando a prática social e equacionando seus problemas com vista a sua superação. Essa instrumentalização não deve ser compreendida no sentido tecnicista, como nos alerta Saviani (2012, p. 71): "Obviamente, não cabe entender a referida instrumentalização em sentido tecnicista. Trata-se da apropriação pelas camadas populares das ferramentas culturais necessárias à luta social que travam diuturnamente para se libertar das condições de exploração em que vivem."

O trabalho docente, nessa perspectiva, gera uma original forma de entender a realidade, indo do empírico ao concreto por meio das abstrações da mente e elevando a compreensão dos sujeitos acerca da estrutura e da superestrutura, possibilitando-os atingir a catarse, ou o sintetismo conceitual, isto é, a compreensão orgânica da realidade (MAIA, 2017).

A questão que nos colocamos é sobre como atingir esse nível educacional, como responder às disparidades entre o desenvolvimento científico e tecnológico, por um lado, e às condições precárias em que vive a maior parte da humanidade, por outro. Viajamos à Lua, e não eliminamos a fome do planeta.

A princípio, a forma de assegurar o acesso a uma educação de qualidade compreende, essencialmente, a intervenção do Estado. Inobstante, se o Estado está composto como estrutura entrelaçada com as determinidades do modo de produção capitalista, seria possível concebê-lo como facilitador do acesso a uma educação não apenas de qualidade, mas crítica? Não só a escola, mas o Estado, principalmente, comporta-se como aparelho ideológico. Aquele, do Estado, e este, do sujeito automático, nomeadamente, o Capital. Sob essas condições, como seria possível transformar a educação, a partir do Estado, se este se apresenta efetivamente como uma apólice de seguros para a manutenção da lógica capitalista?

\title{
4 Direito à educação, ideologia e forma jurídica
}

Na sociedade civil moderna, ou seja, na sociedade civil burguesa (bürgelische Gesellschaft), a organização das bases e processos estruturais que configuram o espaço social é decidida, ou mediada, pela autoridade do Estado. Essa decisão se dá através do Direito e é por ele fundamentada. Portanto, 
para pensar mudanças efetivas e globais no âmbito educacional, é preciso pensar antes as premissas e o conteúdo que fundam a relação entre direito e educação.

$O$ direito à educação encontra-se entre o rol de direitos fundamentais assegurados pelo Direito constitucional, cuja previsão legal encontra-se positivada no art. $6^{\circ}$ da Constituição Federal, dispositivo normativo que estatui o conjunto dos direitos sociais. Além disso, o tema "educação" pode ser encontrado, com propósitos diversos, ao longo de toda a Constituição Federal (v.g., nos art. 6 , 23, 24, 30 e 144), mas uma previsão estrutural e programática do termo está situada na seção I do capítulo III da Constituição de 1988. Segundo o art. 205: "A educação, direito de todos e dever do Estado e da família, será promovida e incentivada com a colaboração da sociedade, visando ao pleno desenvolvimento da pessoa, seu preparo para o exercício da cidadania e sua qualificação para o trabalho" (BRASIL, 1988).

Nossa reflexão tem por hipótese e objeto o fato de que é necessária uma análise material e dialética do direito à educação. Para uma abordagem crítica do tema, é forçoso indagar: Quais são, efetivamente, o conteúdo e a orientação dos programas educacionais? A educação está a serviço de quem? Ou melhor, de quê? Como exposto anteriormente, a teorias pedagógicas tradicionais - que dominam a hegemonia teórica do campo da educação - não possuem qualquer pano de fundo crítico para avaliar esses fundamentos. De modo geral, elas buscam apenas contemplar o mote da "formação cidadã". Mas a educação deve ser entendida em aspectos outros que não apenas sob o espectro da "formação do cidadão".

Considerada apropriadamente, a educação se trata, na verdade, de um complexo dispositivo ${ }^{5}$ que produz processos de subjetivação, isto é, que constitui sujeitos, matrizes epistemológicas, significações psíquicas e práticas concretas. Processos que, de imediato, não são perceptíveis. Integram nossa certeza sensível e outras figuras mais simples de nossa consciência, mas exigem um movimento de racionalização mais refinado para serem compreendidos efetivamente.

As diretrizes e bases da educação reproduzida nos espaços sociais não nos deixa entrever seus efeitos reais. Ela está encoberta pelas brumas da ideologia, apresentando-se em sua forma mistificada. Ora, isto não quer dizer que a educação é de todo um dispositivo ilusório, que deve ser "colocado de pé". O conceito de ideologia não deve ser tomado prematuramente em seu sentido trivial. A ideologia deve ser entendida como um processo de mistificação da realidade que está definitivamente assentado sobre bases reais, materiais, e que, portanto, como afirmado de antemão, produz efeitos reais. ${ }^{6}$ Esses efeitos são uma reverberação das ressonâncias de uma ideologia que é constituída como ideologia dominante, e a educação é um dos institutos elementares de composição dessa ordem simbólico-normativa.

[...] a escola (mas também outras instituições do Estado, como a Igreja ou outros aparelhos como o Exército) ensinam o 'know-how' mas sob formas que asseguram a submissão à ideologia dominante ou o domínio de sua 'prática'. Todos os agentes da produção, da exploração e da repressão, sem falar dos 'profissionais da ideologia' (Marx) devem estar de uma forma ou de outra 'imbuídos' desta ideologia para desempenhar 'conscienciosamente' suas tarefas, - seja a de explorados (os operários), seja a de exploradores (os capitalistas), seja a de auxiliares na exploração (os quadros), seja a de grandes sacerdotes da ideologia dominante (seus 'funcionários') etc... (ALTHUSSER, 1985, p. 58-59).

\footnotetext{
Agamben (2009), a partir de algumas releituras de Foucault sobre a governabilidade, a biopolítica e as relações de poder, busca, em um pequeno ensaio, recuperar e reutilizar a noção de dispositivo conforme empregamos aqui. Trata-se de um conjunto heteróclito de complexos linguísticos e não linguísticos; de leis, imagens, signos, discursos e instituições; resultante de relações de poder e saber que exercem concretamente uma função estratégica. Nesse sentido, Agamben (2009) afirma: "[...] chamarei literalmente de dispositivo qualquer coisa que tenha de algum modo a capacidade de capturar, orientar, determinar, interceptar, modelar, controlar e assegurar os gestos, as condutas, as opiniões e os discursos dos seres viventes. Não somente, portanto, as prisões, os manicômios, o Panóptico, as escolas, a confissão, as fábricas, as disciplinas as medidas jurídicas etc., cuja conexão com o poder é num certo sentido evidente, mas também a caneta, a escritura, a literatura, a filosofia, a agricultura, o cigarro, a navegação, os computadores, os telefones celulares e - por que não - a própria linguagem, que talvez é o mais antigo dos dispositivos, em que há milhares e milhares de anos um primata - provavelmente sem se dar conta das consequências que se seguiriam - teve a inconsciência de se deixar capturar" (AGAMBEN, 2009, p. 40-41).

6 Ressaltamos, porém, que não há forma pura do real. A ideologia não é estática, mas dinâmica, devir constante. Ela opera a permanente mistificação do real, a manutenção da impureza e do disfarce das práticas teóricas, por isso é preciso um incessante e persistente processo de desmitificação e purificação das ideologias que contaminam a ciência. Nessa esteira, Althusser (2015) aduz: "[...] não basta rejeitar o dogmatismo da aplicação das formas da dialética e confiar na espontaneidade das práticas teóricas existentes, pois sabemos que não existe prática teórica pura, ciência totalmente nua, que estaria para sempre em sua história de ciência, preservada por sabe-se lá qual graça de ameaças e ataques do idealismo, ou seja, das ideologias que a assediam; sabemos que não existe ciência 'pura' a não ser com a condição de purifica-la incessantemente, ciência livre dentro da necessidade de sua história, a não ser com a condição de libertá-la incessantemente da ideologia que a ocupa, a habita ou a vigia" (ALTHUSSER, 2015, p. 139).
} 
Essa ideologia dominante aparece como consequência da organização da infraestrutura e da superestrutura que arquitetam o edifício da sociedade moderna, isto é, capitalista ${ }^{7}$. Desse modo, é imperioso entender os movimentos e mecanismos que engendram a dialética entre ambos, a fim de compreender precisamente que a causa e o efeito desses processos é um todo estruturado que configura e reproduz dada forma de sociabilidade. Esse todo estruturado é a totalidade, o conjunto de determinações que compõem a totalidade concreta, ou, ainda, o estado de coisas presente.

Essa relação infraestrutura-superestrutura poder ser entendida, segundo Althusser, através de uma metáfora cuja figura central é a de um edifício, que representa a totalidade capitalista. Segundo ele, toda a sociedade está arranjada numa estrutura organizacional fundada sobre duas instâncias constituídas por uma oposição negativa, que estabelece uma relação dialética entre a infraestrutura - a base econômica (as relações de produção e a unidade das forças produtivas) - e a superestrutura, constituída por uma instância ideológica (moral, jurídica, religiosa, etc.) e outra jurídico-política (direito e Estado). (ALTHUSSER, 1985, p. 60).

Por essa lógica, a educação se apresentaria como uma superestrutura cuja função, por excelência, pode ser resumida à formação e universalização de um determinado regime de racionalidade e compreensão da realidade. Não apenas o conteúdo da produção desse regime, mas também o modo através do qual ele se articula, produz uma determinada percepção dos objetos compreendidos por ele que os mistifica, criando significados e reproduzindo uma dada ideologia particular.

Disso decorre que a "juridicização" do acesso à educação acaba por instituir um duplo filtro ideológico, já que ela é apresentada não só como um modo de "formação da consciência cidadã", mas também, através da força de lei, essa formação de consciência aparece como um processo de subjetivação compulsório e imprescindível. No fundo, o apelo do acesso global à educação - no formato atual - é, na verdade, uma ode à formação da consciência burguesa, ou seja, da consciência do homem moderno (egoísta, consumista, atomizado e explorado), o que produz um singular modelo jurídico e antropológico que é, precisamente, uma das condições de funcionamento da lógica capitalista.

Aqueles que realizam a troca devem ser egoístas, isto é, devem guiar-se pelo cálculo econômico nu e cru; de outro modo, a relação de valor não poderá se mostrar como uma relação necessária socialmente. Aqueles que realizam a troca devem ser portadores de direitos, ou seja, ter a possibilidade da decisão autônoma, pois sua vontade deve 'residir nas coisas'. Por fim, aqueles que realizam a troca encarnam o princípio da equivalência entre pessoas humanas, pois na troca todos os tipos de trabalho equiparam-se uns aos outros e reduzem-se ao trabalho humano abstrato (PACHUKANIS, 2017, p. 154).

\footnotetext{
"Sociedade capitalista" e "sociedade moderna" são expressões idênticas. Afirmar que o capitalismo é moderno ou que a modernidade é capitalista é tautologia. O fenômeno central que caracteriza a passagem da Idade Média e da pré-modernidade para a modernidade é, propriamente, a acumulação primitiva do capital, a qual Marx descreve detalhadamente na obra "O capital". O início da modernidade é, portanto, o fim do modo de produção feudal e a consolidação do modo de produção capitalista. Este é o entendimento expresso de Marx, também consignado no "Manifesto Comunista". Vejamos: "A sociedade burguesa moderna, que brotou das ruínas da sociedade feudal, não aboliu os antagonismos de classe. Não fez mais do que estabelecer novas classes, novas condições de opressão, novas formas de luta em lugar das que existiram no passado. Entretanto, em nossa época, a época da burguesia, caracteriza-se por ter simplificado os antagonismos de classe. A sociedade divide-se cada vez mais em dois campos opostos, em duas grandes classes em confronto direito: a burguesia e o proletariado" (MARX, 2007, p. 40-41). Essa passagem do feudalismo para o capitalismo/modernidade está marcada, fundamentalmente, pela ascensão da burguesia como classe dominante e inconteste. Em outra passagem próxima, Marx (2007) ressalta a força revolucionária da burguesia e sublinha o seu papel enquanto pioneira do processo de modernização, principal responsável pela ruptura com o modo de produção feudal, e pela consolidação do modo de produção capitalista: "[...] a própria burguesia moderna é o produto de um longo processo de desenvolvimento, de uma série de transformações no modo de produção e de circulação. Cada etapa da evolução percorrida pela burguesia foi acompanhada de um progresso político correspondente. Classe oprimida pelo despotismo feudal, associação armada e autônoma na comuna, aqui república urbana independente, ali terceiro estado tributário da monarquia; depois, durante o período manufatureiro, contrapeso da nobreza na monarquia feudal ou absoluta, base principal das grandes monarquias, a burguesia, com o estabelecimento da grande indústria e do mercado mundial, conquistou, finalmente, a soberania política exclusiva no Estado representativo moderno. O executivo no Estado moderno não é senão um comitê para gerir os negócios comuns de toda a classe burguesa. A burguesia desempenhou na História um papel iminentemente revolucionário. Onde quer que tenha conquistado o poder, a burguesia destruiu as relações feudais, patriarcais e idílicas. Rasgou todos os complexos e variados laços que prendam o homem feudal a seus 'superiores naturais', para só deixar subsistir, de homem para homem, o laço do frio interesse, as duras exigências do 'pagamento à vista'. Afogou os fervores sagrados da exaltação religiosa, do entusiasmo cavalheiresco, do sentimentalismo pequeno-burguês nas águas geladas do cálculo egoísta. Fez da dignidade pessoal um simples valor de troca; substituiu as numerosas liberdades, conquistadas duramente, por uma única liberdade sem escrúpulos: a do comércio. Em uma palavra, em lugar da exploração dissimulada por ilusões religiosas e políticas, a burguesia colocou uma exploração aberta, direita, despudorada e brutal" (MARX, 2007, p. 41-42).
} 
O que assegura a manutenção do véu mistificante que encobre o conteúdo efetivo do fundamento dos processos educacionais - a formação e manutenção da consciência egoísta ${ }^{8}$ - não é apenas a ideologia moral que exige a formação de sujeitos "cidadãos", mas também uma ideologia jurídica, que tem como objetivo imediato manter as condições que viabilizam e dão consistência ao objetivo mediato e central: garantir a produção e circulação de mercadorias e a valorização do valor. A ideologia jurídica se mostra, assim, como semblante mistificado da forma jurídica do capital, o anverso da forma mercadoria. ${ }^{9}$

A ideologia jurídica nos faz viver fora das relações de exploração e subordinação, ela nos faz vier em um outro mundo, que nos aparece como uma formação imaginária que produz uma peculiar distorção que é, ao mesmo tempo, alusão ao real e ilusão do real, e que, portanto, não pode ser 'corrigida' ou 'dissolvida' pela exposição à luz da verdade da razão (NAVES, 2014, p. 103).

O que a ideologia jurídica mistifica então? A própria relação social. As relações sociais são convertidas, automática e instantaneamente, em relações jurídicas. Se os próprios indivíduos só existem socialmente enquanto sujeitos de direito, toda a relação entre indivíduos presentes numa mesma sociedade é, desde logo, uma relação entre sujeitos de direito e, por conseguinte, uma relação jurídica. O Direito, ao estabelecer as condições a partir das quais a produção e a circulação de mercadorias pode se reproduzir, apresentase como a forma jurídica necessária para garantir a reprodução do modo de produção capitalista. A forma jurídica e a forma mercadoria se estabelecem e se asseguram mutuamente. Aquela gera a forma jurídica, a qual garante a manutenção das condições que viabilizam a economia capitalista.

[...] a 'gênese' (genezis) da forma do direito se encontra na relação de troca; a forma jurídica é o 'reflexo inevitável' (neizbejnymotprajeniem) da relação dos proprietários de mercadorias entre si; o princípio da subjetividade jurídica 'decorre com absoluta inevitabilidade' (vytekaiut s absoliutnoineizbejnost'iu) das condições da economia mercantil-monetária; esta economia mercantil é a 'condição prévia fundamental' (osnovnoipredposylkoi), o 'momento fundamental e determinante' (osnovnymopredeliaschimmomentom) do direito; a forma jurídica é 'gerada' (porojdaet) pela forma mercantil; a relação econômica de troca 'deve existir' (doljnobyt') para que 'surja' (vozniklo) a relação jurídica; a relação econômica é a 'fonte' (istotchnikom) da relação jurídica (NAVES, 2008, p. 53-54). ${ }^{10}$

Mas quais são, propriamente, as condições que asseguram a reprodutibilidade do sistema mercantil capitalista? Como já mencionado, para que o intercâmbio de mercadorias seja possível, é preciso que existam sujeitos que façam suas vontades residirem nelas. A mercadoria é, a rigor, o recipiente reificado que contém a propriedade abstrata do valor; a diversidade concreta das qualidades e determinidades do produto são convertidas em unidade simples de valor abstrato, cuja característica essencial é a possibilidade de

Em Marx, o indivíduo egoísta surge como um dado "natural" da sociedade civil burguesa. A configuração da sociabilidade moderna traz consigo, como fundamento, efeito e condição, o próprio homem enquanto sujeito egoísta. O indivíduo, tragado pela ficção jurídica e convertido em cidadão, não é nada mais nada menos que o homem egoísta, concentrado unicamente em suprir suas carências. Vejamos: "A constituição do Estado político e a dissolução da sociedade burguesa nos indivíduos independentes - cuja relação é baseada no direito, assim como a relação do homem que vivia no estamento e na guilda era baseada no privilégio - se efetiva em um só e mesmo ato. O homem, na qualidade de membro da sociedade burguesa, o homem apolítico, necessariamente se apresenta então como o homem natural. Os droits $d$ l'homme se apresentam como droits naturels, pois a atividade consciente se concentra no ato político. O homem egoísta é o resultado passivo, que simplesmente está dado, na sociedade dissolvida, objeto da certeza imediata, portanto, objeto natural. A revolução política decompõe a vida burguesa em seus componentes sem revolucionar esses mesmos componentes nem submetê-los à crítica. Ela encara a sociedade burguesa, o mundo das necessidades, do trabalho, dos interesses privados, do direito privado, como o fundamento de sua subsistência, como um pressuposto sem qualquer fundamentação adicional e, em consequência, como sua base natural. Por fim, o homem na qualidade de membro da sociedade burguesa é o que vale como o homem propriamente dito, como o homme em distinção ao citoyen, porque ele é o homem que está mais próximo de sua existência sensível individual, ao passo que o homem político constitui apenas o homem abstraído, artificial, o homem na forma do indivíduo egoísta, o homem verdadeiro, só na forma do citoyen abstrato" (MARX, 2010, p. 53).

9 "A troca de mercadorias pressupõe uma economia atomizada. A conexão entre as unidades econômicas privadas isoladas estabelece uma conexão, caso a caso, por meio de contratos. A relação jurídica entre os sujeitos é apenas outro lado das relações entre os produtos do trabalho tornados mercadoria" (PACHUKANIS, 2017, p. 97).

10 Ainda: "A forma jurídica nasce somente em uma sociedade na qual impera o princípio da divisão do trabalho, ou seja, em uma sociedade na qual os trabalhos privados se tornam trabalho social mediante a intervenção de um equivalente geral. Em tal sociedade mercantil, o circuito de trocas das mercadorias só se realiza se uma operação jurídica - o acordo de vontades equivalentes - for introduzida. Ao estabelecer um vínculo entre a forma direito e a forma mercadoria, Pachukanis (2017) mostra que o direito é uma forma que reproduz essa equivalência, essa 'primeira ideia puramente jurídica' a que ele se refere. A mercadoria é a forma social que necessariamente deve tomar o produto quando realizado por trabalhos privados independentes entre si, e que só por meio da troca realizam seu caráter social. O processo do valor de troca, assim, demanda para que se efetive um circuito de trocas mercantis, um equivalente geral, um padrão que permita 'medir' o quantum de trabalho abstrato está contido na mercadoria. Portanto, o direito está indissociavelmente ligado à existência de uma sociedade que exige a mediação de um equivalente geral para que os diversos trabalhos privados independentes se tornem trabalho social" (NAVES, 2008, p. 57-58). 
ser trocada por outras mercadorias através de uma medida equivalente. Para que o processo de circulação dessas trocas se concretize, é necessário que a equivalência exista não apenas entre mercadorias, mas também entre sujeitos. Se, para que as mercadorias possam ser trocadas, é preciso que uma vontade lhes dê movimento, também é preciso que os sujeitos sejam capazes de emitir essa vontade; vontade que pressupõe a atribuição de uma consciência livre. Essa atribuição, efetuada através da forma jurídica, concede aos sujeitos de direito não apenas a liberdade, mas uma equivalência absoluta entre todo e qualquer sujeito: se todo sujeito de direito é livre, logo todos os sujeitos de direito são igualmente livres. A sociedade mercantil é, antes de tudo, o grande espetáculo teatral dos proprietários de mercadoria, aos quais é permitido fingir - e acreditar - ter atributos inatos que, de fato, não têm (PACHUKANIS, 2017, p. 119-120). ${ }^{11}$

Ora, a pergunta mais uma vez nos aparece: Como pensar essas novas formas de vida quando estamos diante de um espetáculo ${ }^{12}$ que ofusca qualquer vislumbre para além de suas cortinas e panos de fundo?

\section{Bloco histórico e disputa hegemônica}

É possível pensar um processo de transição que permita novas suturas no regime de sociabilidade e nas formas de organização social correntes? A sutura implica que haja a possibilidade de ruptura, de corte e reorganização dessas formas, cujo funcionamento está submetido e orientado pelas produções ideológicas da lógica capitalista.

Ora, o que determina o sentido da produção ideológica e o conteúdo dos seus fluxos é justamente o resultado do jogo de forças em disputa pela hegemonia. Em suma, as transformações socioeconômicas em geral, os dobramentos e desdobramentos do imaginário social resultante da configuração da estrutura jurídico-educacional, os processos de subjetivação produzidos por dispositivos de natureza pedagógica, etc., são produtos de uma relação de forças que estabelece um bloco histórico. ${ }^{13}$ Esse bloco histórico orienta as configurações da máquina ideológica ao mesmo tempo em que é resultante dela. Para constituir novos fluxos ideológicos, é preciso, portanto, reconfigurar essa máquina. Ou destituí-la.

Não seria o caso, então, de se repensar as formas de constituição de um bloco histórico? Isto é, pensar na articulação de novas práticas teóricas que componham uma nova configuração social? Pensar a disputa do espaço sociopolítico a partir de um novo bloco histórico? Uma disputa por novas formas de hegemonia? Para pensar essa tarefa, a hegemonia deve ser tomada em seu sentido pleno. Não se trata, simplesmente, de uma disputa política ou ideológica.

[O] conceito de hegemonia representa, para além do progresso político-prático, um grande progresso filosófico, já que implica e supõe necessariamente uma unidade intelectual e uma ética adequada a uma concepção do real que superou o senso comum e tornou-se crítica, mesmo que dentro de limites ainda restritos (GRAMSCI, 1999, p. 104).

Dessa forma, o conceito de hegemonia implica uma disputa, também e principalmente, no próprio plano filosófico-linguístico-epistemológico. Trata-se de retomar a língua e a potência da palavra; de reinventar o próprio discurso, constituindo os meios para a realização da absoluta negação do atual bloco histórico e hegemônico, permitindo uma insurgência até mesmo contra essa gramática que se instalou em favor de

11 Também importa destacar: "Consequência da diversidade natural das propriedades úteis, um produto aparece na forma de mercadoria apenas como um simples invólucro do valor, e os aspectos concretos do trabalho humano diluem-se no trabalho humano abstrato como criador de valor - do mesmo modo que a diversidade concreta de relações do homem com as coisas surge coo uma vontade abstrata do proprietário e todas as particularidades concretas que diferenciam um representante da espécie de homo sapiens de outro diluem-se na abstração do homem em geral como sujeito de direito" (PACHUKANIS, 2017, p. 121).

12 "Toda a vida das sociedades nas quais reinam as modernas condições de produção se apresenta como uma imensa imagem de espetáculos. Tudo o que era vivido diretamente se tornou uma representação" (DEBORD, 1997, p. 13). O espetáculo da sociedade moderna, assim, não é uma sequência de imagens, luzes e performances; ele é a própria totalidade de relações entre pessoas. Na sociedade capitalista, as relações sociais são todas mediadas por imagens, isto é, por representações que, na verdade, foram objetivadas, materializadas. O espetáculo é um fenômeno imagético fixo, cujo encadeamento de movimentos no fundo é apenas uma ilusão. A sensação de liberdade e de progresso efetivo é a mais deprimente das representações nas quais o sujeito escolhe acreditar. O sujeito moderno vive livremente preso numa ficção de si mesmo.

13 "A estrutura e a superestrutura formam um 'bloco histórico', isto é, o conjunto complexo e contraditório das superestruturas é o reflexo do conjunto das relações sociais de produção" (GRAMSCI, 1999, p. 250). 
uma determinada lógica - a lógica do capital - e contra qualquer contestação, até mesmo no campo da linguagem.

Mas, em termos dialéticos, é impossível a conquista parcial de cada um desses espaços isoladamente, seja do campo ideológico, seja do campo político. A obtenção da hegemonia, principalmente no campo da produção ideológica por si só, é impossível. A captura da máquina ideológica depende da assunção das bases materiais que servem de substrato para a produção ideológica. Em outras palavras, a infraestrutura que alimenta as superestruturas, a lógica que determina o funcionamento e o movimento das estruturas sociais, é o elemento determinante para a constituição de um novo bloco histórico. A fundação de um novo bloco histórico depende da transformação da sociabilidade moderna, isto é, da ruptura com o modo de produção capitalista e a desconstituição das bases econômicas que sustentam as atuais formas de metabolismo social.

Nossa proposição pode ser sintetizada nos seguintes termos: O início desse processo depende de uma estratégia revolucionária que contemple duas tarefas centrais: 1) o estabelecimento de um aparelho hegemônico que dispute a máquina ideológica: ${ }^{14}$ e 2 ) a dissolução radical do modo de produção capitalista e a produção de modelos genéricos de sociabilidade alternativa. Ambas as tarefas estão interligadas dialeticamente e, por essa razão, dependem uma da outra: a efetiva realização de uma subordina-se à concretização contínua e concomitante da outra.

\section{Conclusão}

Com isso, estão finalmente lançadas algumas bases conceituais para uma crítica ontológica do estado de coisas atual, que é capaz de nos fornecer alguns elementos essenciais para repensar as bases estruturais que sustentam o capitalismo atual. A partir de uma crítica das categorias trabalho, direito e educação, pudemos entrever algumas formas de constituição e de reprodução da lógica do capital através das quais é possível disputar o monopólio hegemônico superestrutural e, ao mesmo tempo, propor novas formas da vida genérica, ou uma forma de vida que implique a abertura ontológica à autorrealização do homem e inaugure a possibilidade da formação de uma consciência efetivamente livre.

Não pretendemos que estas breves linhas funcionem como alguma espécie de fórmula mágica para uma ruptura ontológica, mas que elas possam sirvam como pequenas chaves conceituais para abrir portas para possíveis mundos por vir. O ritmo acelerado de transformação e atualização violenta do real nos impõe a necessidade, cada vez mais inadiável, de compor novas narrativas e de reinventar nosso horizonte de expectativas. O capitalismo fugaz e espectral do século XXI assinalou o fim das antigas narrativas do progresso; presenciamos diariamente as afirmações e reafirmações cada vez mais inegáveis do colapso do futuro. É preciso inventar um novo futuro. Por essa razão, propomos esse pequeno, mas precioso e necessário, passo ao por vir.

\section{Referências}

AGAMBEN, Giorgio. O que é o contemporâneo? e outros ensaios. Tradução de Vinicius Nicastro Honesko. Chapecó: Argos, 2009.

ALTHUSSER, Louis. Aparelhos ideológicos de Estado: nota sobre os aparelhos ideológicos de Estado (AIE). Tradução de Walter José Evangelista e Maria Laura Viveiros de Castro. 6. ed. Rio de Janeiro: Graal, 1985.

ALTHUSSER, Louis. Por Marx. Tradução de Maria Leonor F. R. Loureiro. Campinas: UNICAMP, 2015.

\footnotetext{
14 "A realização de um aparelho hegemônico, enquanto cria um novo terreno ideológico, determina uma reforma das consciências e dos métodos de conhecimento, é um fato de conhecimento, um fato filosófico. Em linguagem crociana: quando se consegue introduzir uma nova moral conforme a uma nova concepção do mundo, termina-se por introduzir também esta concepção, isto é, determina-se uma completa reforma filosófica" (GRAMSCI, 1999, p 325).
} 
BRASIL. Constituição (1988). Constituição da República Federativa do Brasil. Brasília, Senado, 1988. Disponível em: <http://www.planalto.gov.br/ccivil_03/constituicao/constituicaocompilado.html>. Acesso em: 12 jun. 2017.

DEBORD, Guy. A sociedade do espetáculo. Tradução de Estela dos Santos Abreu. Rio de Janeiro: Contraponto, 1997.

DUAYER, Mario. Crítica ontológica em Marx. In: PAULO NETTO, José (Org.). Curso livre Marx-Engels: a criação destruidora. São Paulo: Boitempo: Carta Maior, 2015. p. 115-137.

FRANKLIN, Karen. Os conceitos de Doxa e Episteme como determinação ética em Platão. Educar, Curitiba, n. 23, p. 373-376, 2004.

GRAMSCI, Antonio. Cadernos do cárcere - Introdução ao estudo da filosofia. A filosofia de Benedetto Croce. Tradução de Carlos Nelson Coutinho. Rio de Janeiro: Civilização Brasileira, 1999. v. I.

JAPPE, Anselm. As aventuras da mercadoria. Tradução de José Miranda Justo. 2. ed. Lisboa: Antígona, 2006.

MAIA, Jorge Sobral da Silva. Trabalho pedagógico e formação continuada de professores em educação ambiental crítica na escola pública. Guarapuava: Ambiência, 2017.

MAIA, Jorge Sobral da Silva. Educação ambiental crítica e formação de professores: construção coletiva de uma proposta na escola pública. 2011. 249 f. Tese (Doutorado em Educação para a Ciência). Faculdade de Ciências, UNESP, Bauru, 2011.

MARTINS, Ligia Márcia; RABATINI, Vanessa Gertrudes. A concepção de cultura em Vigotski: contribuições para a educação escolar. Psicologia Política, São Paulo, v. 11. n. 22, p. 345-358, jul.-dez. 2011. Disponível em: <http://pepsic.bvsalud.org/pdf/rpp/v11n22/v11n22a11.pdf >. Acesso em: 05 abr. 2016.

MARX, Karl; ENGELS, Friedrich. Manifesto comunista. Tradução de Álvaro Pina. São Paulo: Boitempo, 2007.

MARX, Karl; ENGELS, Friedrich. A sagrada família: ou A crítica da Crítica contra Bruno Bauer e consortes. Tradução de Marcelo Backes. São Paulo: Boitempo, 2011.

MARX, Karl. Manuscritos econômico-filosóficos. Tradução de Jesus Ranieri. 4. reimp. São Paulo: Boitempo, 2010.

MARX, Karl. O capital: crítica da economia política. Livro I: o processo de produção do capital. Tradução de Rubens Enderle. São Paulo: Boitempo, 2013.

MARX, Karl. Sobre a questão judaica. Tradução de Nélio Schneider. São Paulo: Boitempo, 2010.

MOREIRA, Marcos Antonio; MASSONI, Neusa Teresinha. Epistemologias do Século XX. São Paulo: E.P.U., 2011.

MARSIGLIA, A. C. G. A prática pedagógica histórico-crítica na educação infantil e ensino fundamental. Campinas: Autores Associados, 2011.

MENESES, Paulo. Entfremdung e Entäusserung. Ágora Filosófica, Recife, ano 1, n. 1, p. 27-42, jan.jun. 2001. Disponível em: <http://www.unicap.br/Arte/ler.php?art_cod=492>Acesso em: 08 mar. 2017.

NAVES, Márcio Bilharinho. A questão do direito em Marx. São Paulo: Outras Expressões; Dobra Universitário, 2014.

NAVES, Márcio Bilharinho. Marxismo e direito: um estudo sobre Pachukanis. São Paulo: Boitempo, 2008.

PACHUKANIS, Evguiéni. Teoria geral do direito e marxismo. Tradução de Paulo Vaz de Almeida. São Paulo: Boitempo, 2017.

POSTONE, Moishe. Tempo, trabalho e dominação social: uma reinterpretação da teoria crítica de Marx. Tradução de Amilton Reis e Paulo Cézar Castanheira. São Paulo: Boitempo, 2014. 
SAVIANI, Dermeval. Escola e democracia. 42. ed. Campinas: Autores Associados, 2012.

SAVIANI, Dermeval. Educação: do senso comum a consciência filosófica. 17. ed. Campinas: Autores Associados, 2007.

SAVIANI, Dermeval. Pedagogia histórico-crítica: primeiras aproximações. 9. ed. Campinas: Autores Associados, 2005.

SAVIANI, Dermeval. Escola e democracia. 34. ed. Campinas: Autores Associados, 2001.

SOUZA JUNIOR, Justino. Marx e a crítica da educação: da expansão liberal democrática à crise regressivo-destrutiva do Capital. 2. ed. Aparecida/SP: Ideias \& Letras, 2010.

Recebido em: 05/07/2017

Aprovado em: 26/02/2018 